\title{
Mulleres na escuridade: estudo das personaxes femininas n' $O$ corazón do negror, de Joseph Conrad
}

\author{
Cecilia Fernández Santomé
}

Universidade de Santiago de Compostela

[Recibido, 13 outubro 2019; aceptado, 26 novembro 2020]

\begin{abstract}
[Fernández Santome, C. (2020). Mulleres na escuridade: estudo das personaxes femininas n'O corazón do negror, de Joseph Conrad. Boletín Galego de Literatura, 57, "Notas", 31 -44] DOI http://dx.doi.org/10.15304/bgl.57.7172
\end{abstract}

RESUMO Publicado en 1902, O corazón do negror axiña foi considerado como un testemuño de excepción -ao que logo virían sumarse Pasaxe á India, de E. M. Forster (1924) ou Memorias de África, de Karen Blixen (1937)- sobre as dinámicas colonialistas europeas no apoxeo da súa implantación nos territorios dominados. Joseph Conrad escribe dende a experiencia persoal para retratar dun xeito cru as sombras que se cinguen sobre os mecanismos de explotación da África ignota, a negrura moral de quen os dirixen, só equiparábel á da propia selva. O seu é un relato de ousadía, de ambición e vontade de transcendencia, valores que sociedades como as europeas percibían daquela como inherentes ao xénero masculino. Mariñeiros, comerciantes, peregrinos da metrópole pululan polas terras africanas. Pero que hai das mulleres? Que rol desempeñan na novela e, por extensión, na colonización aos ollos de Conrad? O obxectivo deste artigo é ofrecer unha aproximación á cuestión mediante unha lectura crítica do texto.

PALABRAS CHAVE: O corazón do negror; Joseph Conrad; novela colonial; colonialismo; personaxes femininos.

ABSTRACT First published in 1902, Heart of Darkness was soon considered (together with E. M. Forster's A Passage to India, 1924, and Out of Africa, by Karen Blixen, 1937) an exceptional testimony of the European power dynamics in the colonies. Based on his experience, Joseph Conrad depicted some not so bright aspects of the British presence in Africa. Darkness represents not just the unknown side of the continent but also the corrupted souls of most of the colonial agents. This is a story of bravery, ambition, profit and glory -values traditionally perceived as inherent to masculinity. Metropolitan seamen, traders and pilgrims navigate the heart of that mysterious land. But what about women? What part do they play in this novel and, by extension, in the colonization process according to Conrad's writing? The aim at this article is to study the configuration of female characters in Heart of Darkness and their relevance for the plot.

KEYrWORD: Heart of Darkness; Joseph Conrad; novel written during colonisation; colonialism; female characters.

Se ben os movementos colonizadores semellan ser parte intrínseca da evolución e expansión das comunidades humanas (a paleoantropoloxía cualifica como tal, por exemplo, a migración cara outras latitudes de homínidos 
procedentes de África; como tamén o serían, xa que logo, as expansións fenicia, romana e grega na Idade Antiga; a incursión árabe na Península Ibérica ou o espolio de América), os iniciados no século XVIII e afianzados no XIX posúen resonancias particulares dada a súa extensión xeográfica e temporal, así como o impacto económico, político e social que tiveron no século XX.

Segundo o dicionario en liña da Real Academia Galega, "colonizar" evoca o proceso mediante o cal alguén se establece nun lugar (xeralmente despoboado) co obxectivo de cultivalo, habitalo, exploralo. Unha definición que, levada ao plano da política adquire matices que convén ter en conta. Porque, fronte á épica do Afastado Oeste ou os moito máis próximos plans do Instituto Nacional de Colonización español na década dos 50, o paradigma da ocupación de territorios remotos nos continentes africano e asiático ao longo do século XIX non partiu dun escenario de táboa rasa. As poboacións indíxenas houberon de ser sometidas mediante o exercicio da forza (fose esta militar, relixiosa, cultural ou económica).

Esa acepción da colonización -na que se inscribe a obra de Joseph Conrad- tiña por base a imposición dos códigos da potencia invasora fronte aos propios da comunidade autóctona en virtude á superioridade estratéxica daquela, sendo os seus obxectivos variados: dende o abastecemento de materias primas valiosas para o desenvolvemento das crecentes actividades industriais metropolitanas até a obtención de minerais preciosos e outros materiais prezados para o comercio de luxo, pasando explotación de man de obra local e a creación dun mercado para os excedentes europeos. Fins que a miúdo foron disimulados ante a opinión pública baixo unha retórica discursiva que apelaba ao deber moral e case que humanitario de facerlles participar das bondades da civilización aos indíxenas, ofrecéndolles a posibilidade de redimirse mediante o coñecemento da fe verdadeira. Unha xustificación filantrópica que n'O corazón do negror queda patente na elocuente reacción da tía de Charlie Marlow, que o bendí como "mensaxeiro da luz" (Conrad, 2013, p. 22), destinado a extirparlles os seus horrendos costumes a eses millóns de ignorantes.

Esa especie de apostolado moderno, herdeiro dos argumentos esgrimidos polos promotores das misións evanxelizadoras da Idade Moderna e que o propio Marlow contempla con escepticismo ("aventureime a insinuar que a compañía operaba con ánimo de lucro” [Conrad, 2013, p. 23]), serviu para lexitimar un complexo sistema de explotación material e humana mentres 
afianzaba unha imaxe certamente idealizada dos acontecementos nas terras sometidas. Así, pódese afirmar que as sociedades metropolitanas vivían na ilusión do prestixio, da gloria e da bonanza, alimentada dende os poderes públicos e as canles de comunicación (véxase, ao respecto, a explicación que ofrece Marlow ao entusiasmo da tía: "naquel momento acababan de correr ríos de tinta e de abrirse moitas bocas para falar daquela trapallada, e a boa muller, que vivía no mesmísimo medio daquela andrómena, deixábase arrastrar" (Conrad, 2013, p. 22).

África é unha constante na conversa pública e privada, convertida nun medio ou nun fin para gobernantes, comerciantes, especuladores, aventureiros, mariñeiros, para tantas acepcións e perfís masculinos como podemos atopar, sen ir máis lonxe, n'O corazón do negror. Mais tamén para as mulleres, aínda que dun xeito notabelmente diferente, como veremos a continuación. Joseph Conrad escribe dende o coñecemento que lle outorga a súa longa experiencia como membro da mariña mercante inglesa durante o apoxeo imperialista do último cuarto do século XIX. Foi testemuña dos cambios da navegación para adaptarse ás necesidades da industria, da adecuación dos barcos aos novos materiais transportados, da modificación dos tempos no mar, da conduta dos seus compatriotas de adopción alén do mar. E eses longos anos embarcado deixaron pegada no seu pensamento e na súa escrita. O escepticismo e unha certa melancolía infíltranse entre as liñas. Hai moito das súas reflexións persoais en personaxes como Marlow, se ben é arriscado, como alerta Zdzisław Najder (2007, p. XII), querer facer del a súa proxección na ficción. Porén, o pouso autobiográfico de textos como Lord Fim (1900), The Mirror of the Sea (1906) e a propia $O$ corazón do negror (1903) pode constituír unha ferramenta de excepción para realizar unha aproximación á visión conradiana da sociedade do seu tempo. E a ela, precisamente, dedicarei o corpo deste artigo, centrando a análise na percepción do papel xogado polas mulleres no marco da carreira imperialista segundo as diversas caracterizacións presentes na súa obra cumio.

Mais antes diso, é obrigado deterse nun dos grandes prexuízos críticos que pesaron sobre Joseph Conrad e condicionaron a recepción desta. A súa asociación profesional co mar foi explotada comercialmente xa no seu tempo, procurándolle unha reputación de autor de aventuras exóticas similar á de Rudyard Kipling ou Herman Melville. Pasou así a engrosar as filas de escritores con voces narrativas auténticas, pois falaban dende a primeira liña, 
dende o coñecemento directo. Dende dentro da acción. Homes que escribían para outros homes, que constituían o público ideal para historias nas que a experiencia feminina era, como moito, periférica e anecdótica. Unha estratexia editorial que se consolidou coa reedición nos seus traballos completos entre os anos 40 e 50 e que ten certas similitudes coa que había de procurarlle a fama, algo máis tarde, a Ernest Hemingway. Neste sentido, é interesante recuperar a xustificación por parte de Graham Hough (1960, p. 214) do escaso éxito de Conrad entre o lectorado feminino, non exenta de paternalismo:

In my experience very few women really enjoy Conrad, and this is not only because the feminine sensibility so often ceases to function at the mere mention of a topsail halyard, but because the characteristic concerns and occupations of the woman's world play such a very small part in Conrad's work.

A inercia publicitaria callou e deu lugar a unha lectura canónica, asumida e reproducida polas seguintes xeracións sen sequera sometela a revisión. Tómense a modo de exemplo diversas lecturas realizadas ao abeiro da crítica postcolonial e feminista, tan en voga entre os anos 60 e 70 do século pasado. Edward Said non dubidou en cualificar as mulleres como un elemento máis na lista do que el denomina "substancias", materiais que empregaba Conrad para organizar os seus relatos. Reducidas á condición de cebo romántico ou de talismán para a fortuna. Susan Jones $(1999$, p. 7) cítaos a el e á escritora Joyce Carol Oates como paradigma dese tipo de interpretación falaz, e apunta: "Meanwhile, some feminist critics continue to interpret Conrad's narratives as unremittingly patriarchal, reading into his presentation of women a blatant and uncomplicated misogyny".

E así, sobre $O$ corazón do negror pesa dende hai décadas un dobre estigma: o de ser un texto procolonial e misóxino. Unha dobre marca que, con todo, se sostén con dificultades nunha lectura atenta e non condicionada. Acaso detrás da distancia entre o escepticismo de Marlow e o materialismo dos seus compañeiros de viaxe non se albisca una liña de pensamento crítica co colonialismo inglés? Non é o realismo nas descricións do territorio e da poboación indíxena, abstraéndose da tentación exotizante ou demonizante que predominaba en relatos de natureza similar, unha xenuína mostra de respecto?

No tocante ás acusacións de misoxinia, sirva para esclarecelas o estudo das personaxes femininas n'O corazón do negror que a continuación se introduce. Unha revisión que, por outra banda, non pode partir senón dun breve repaso 
á propia condición das mulleres na sociedade inglesa -e, en xeral, na Europa occidental- de finais do século XIX e primeiros do XX, pois debe entenderse que é dende esa óptica que Conrad constrúe as personalidades da tía de Marlow ou das empregadas da compañía, por mencionar só dous exemplos.

Dito período enmárcase na denominada "época vitoriana", tempo de desenvolvemento industrial e financeiro ligado á florecente industria e aos capitais derivados. Mais o ritmo expansivo da economía non tiña correspondencia naquilo que algúns chamaban "a moral pública". O conservadorismo marcaba o paso, manifestándose nun moralismo exacerbado, un amplo número de prexuízos e un estrito código de conduta en sociedade.

Homes e mulleres posuían funcións específicas e non debían faltar a elas baixo ningún concepto. Así pois, eles encargaríanse de protexelas de portas para fóra, preservando de calquera perturbación externa esa especie de letargo feminino imposto, mentes elas practicarían a ética do coidado, atendendo as necesidades do cabeza de familia e dos fillos, velando sempre polo bo funcionamento dos asuntos domésticos.

A consideración da muller como un "anxo do fogar" ao que home debía venerar enmascaraba unha abafante limitación da súa iniciativa, reducíndoa ao status de figura decorativa, ama de casa e de cría. O eido público era do dominio dos homes, o privado éralle reservado a elas. Unha división en dúas esferas netamente independentes que se sustentaba na crenza de que só eles posuían a intelixencia requirida para gobernar, xestionar, dirixir e planificar xa fose unha fábrica ou un gabinete político.

Nese contexto, encaixa á perfección a seguinte reflexión do sociólogo neomarxista Pierre Bourdieu (1998, p. 55): “[...] les femmes, soumises à un travail de socialisation qui tend à les diminuer [...] font l'apprentissage des vertus négatives d'abnégation, de résignation e de silence [...]”. Unha teoría que, reflectindo unha realidade estendida, cómpre matizar, pois concorda sobre todo coas circunstancias das burguesas e das aristócratas. As propias urxencias das clases baixas forzaba outro tipo de dinámicas menos rigorosas no tocante, por exemplo, ao traballo feminino fóra da casa. Con todo, tanto unhas coma outras vivían sometidas ao ditado masculino, o que Virginia Woolf (1984, p. 45) definía así: "the masculine point of view [...] governs our lives, [...] sets the standard". 
Tendo en consideración este panorama, cabe poñer en corentena a condena por misóxina da obra de Joseph Conrad. A idea de que apenas introducía mulleres nas súas tramas non pode ser atribuída senón a un prexuízo nacido trala publicación de Tales of Unrest (1898) e Lord fim (1900), carente de validez se consideramos o conxunto da súa produción. Na novela que nos ocupa, sen ir máis lonxe, o balance entre personaxes masculinos e femininos con entidade (e por entidade enténdase que teñan dimensión) é equilibrado: catro homes (Marlow, o capitán, o axente ruso, Kurtz) fronte a catro mulleres (a tía de Marlow, a empregada da compañía, a indíxena e a prometida de Kurtz).

Certo é que ningunha delas ocupa un lugar preeminente na trama. Son secundarias, cando non periféricas na acción. Á fin e ao cabo, "the women are 'out of' the man's world [...]" (Hawthorn, 1999, p. 183), que é o que, en último termo está representado n'O corazón do negror. A distancia que separa o espazo feminino do masculino queda de manifesto na seguinte reflexión de Marlow, que reproduce unha mentalidade dans l'air du temps: "Que curioso é comprobar o lonxe da realidade que viven as mulleres! Habitan un mundo de seu que endexamais existiu e que nunca poderá existir. É demasiado fermoso, sen dúbida; se quixesen construílo, esboroaríase antes do primeiro solpor " (Conrad, 2013, p. 23).

Con todo, sería inexacto afirmar que funcionan como simples comparsas. Porque, malia non ocuparen o centro da escena, a súa intervención ben podería considerarse esencial para o desenvolvemento dos acontecementos. Nese sentido, encaixarían coa interpretación de Edward Said citada con anterioridade, en tanto que pezas percusoras dentro da maquinaria narrativa.

Se n'O corazón do negror os homes levan a cabo unha viaxe da luz (representada pola súa sociedade de orixe) ás tebras (que encarnan os territorios situados no curso superior do río Congo) para volveren ao refuxio da civilización, diríase que as mulleres, se ben rodeadas de confort e seguridade, viven sumidas nunha particular variante da escuridade. Súa é a escuridade derivada da inexperiencia, do descoñecemento da realidade non doméstica, da exclusión da toma de decisións políticas e económicas. Sobre elas pesa o veo da forzosa feliz ignorancia que ningunha esperanza semella capaz de levantar. Lembremos as palabras de Marlow a este respecto, de novo tinguidas dun paternalismo que Johanna M. Smith (1989, p. 183) cualifica de mistificación das relacións de poder home-muller: "elas, refírome ás mulleres, non teñen 
nada que ver, non deberían ter nada que ver. Temos que axudar para que non saian dese fermoso mundo delas, non vaia ser que o noso vaia peor" (Conrad, 2013, p. 88).

Mais, se a consigna era deixalas a un lado das cuestións coloniais, como é que o propio Charlie Marlow se vale delas para poñer en marcha o seu ambicioso plan de aventureiro? Quizais porque na súa carreira por embarcar rumbo a África calquera axuda era benvida ou porque, simplemente, os seus coñecidos lle deran as costas: "Os homes dicían 'Home de Deus!' e non facían nada. E entón, quen o había dicir?, probei coas señoras” (Conrad, 2013, p. 16).

El mesmo admite, escandalizado pola súa ousadía, que usou as redes de contactos femininos do seu entorno para conseguir o seu obxectivo. $\mathrm{O}$ fin xustifica, xa que logo, os medios, aínda que supoña implicar a mulleres en xestións que poden interferir con asuntos masculinos. E aí onde entra en escena a tía, "unha alma cándida chea de entusiasmo" (Conrad, 2013, p. 16), da que non se menciona o nome.

Como xa se apuntou con anterioridade, a carreira colonial non reservaba ningún posto para elas. Fóra de seren as consortes dalgún cargo gobernamental en protectorados ou dominios, a súa presenza nos territorios conquistados era anecdótica, por non dicir inexistente. A súa única oportunidade para participar da aventura africana presentábase en situacións excepcionais como a que expón Marlow. A súa tía vive a emoción da viaxe, a promesa de vivencias e méritos, da gloria persoal por procuración (un trazo que se apreciará tamén na prometida de Kurtz), acompañando coa imaxinación ao seu sobriño, patrocinándoo, sendo o seu anxo da garda: "Escribiu: 'Será todo un pracer. Estou disposta a facer calquera cousa por ti, o que faga falta. É unha idea marabillosa. Coñezo a esposa dun persoeiro moi notábel da Administración e tamén un señor que ten moita influencia con...', etcétera" (Conrad, 2013, p. 16) .

Excluída da experiencia real, aférrase á posibilidade de ser útil á causa dun terceiro. Operando nas sombras, entre bambolinas, manténdose no dominio da escuridade alimenta as ambicións do sobriño. Serve, xa que logo, de ponte entre os desexos del e a súa realización. Dese xeito, dáse unha satisfacción feminina, un xúbilo -non exento dun certo sentimentalismo- obtidos mediante 
o cumprimento da vontade do home. E para iso pon en marcha a engrenaxe do seu tecido social, das súas relacións femininas que, curiosamente, neste caso funcionan coa eficacia da mellor engraxada das diplomacias: "Estaba decidida a non reparar en molestias para colocarme de capitán dun vapor fluvial, se tal era a miña ilusión" (Conrad, 2013, p. 16). Adopta así unha función similar á da fada madriña ou axudante do heroe na narrativa tradicional.

Abonda con que Marlow verbalice as súas expectativas, con que formule un desexo, e este seralle concedido. Cabería preguntarse se a satisfacción do mesmo responde a una mostra de altruísmo da súa tía ou de egoísmo (para saciar indirectamente a súa propia sede de acción, así como para saberse protectora dun futuro e glorioso servidor á causa). É inevitábel que, ante semellante entusiasmo, o sobriño fantasíe co porvir que lle agarda: "pensaban [na compañía] dirixir un imperio ultramarino e facerse de ouro a poder de comerciar" (Conrad, 2013, p. 18).

A tía (instalada en Bélxica, segundo se sobreentende) introdúceo nos círculos adecuados, preséntao, ábrelle as portas e ofrécelle a posibilidade. E nese rol de facilitadora, tomaranlle o relevo as traballadoras da compañía comercial continental á que o home se dirixe para formalizar o seu enrolamento. Dúas mulleres que deixan pegada en Marlow pola súa actitude case robótica e que posúen un atributo cunha fonda carga simbólica: nobelos de la negra coa que fan punto. Igual que unha particular versión das Parcas, encárganse de mover os fíos do destino dos expedicionarios que petan á súa porta. Tiran deles, recóllenos, córtanos. Un simbolismo que evoca, ademais, a tradicional asociación da muller co ciclo vital, pois tanto porta o feto no seu ventre como se mantén a carón do moribundo para acompañalo no seu transo final. Son principio e fin da aventura, alfa e omega. Eficaces, asépticas, mulleres-zombie que apenas reparan na presenza dos que se cruzan no seu camiño.

Moitas veces, xa moi lonxe daquel lugar, había pensar naquelas dúas gardiás da porta da escuridade, a teceren la negra coma se houbese servir de pano mortuorio, unha a guiar, a introducir arreo no ignoto, a outra a escudriñar as faces xoviais e aparvadas con ollos velos e displicentes. (Conrad, 2013, p. 20)

Conrad semella especialmente interesado en que sexan identificadas coas fiandeiras mitolóxicas, pois fai que Marlow exclame: "Ave, vella tecelá de la negra, morituri te salutant” (Conrad, 2013, p. 20). E esa mirada súa, cargada de sabedoría, convértese nun oráculo para Marlow, que le nela o misterio e a 
fatalidade que o axexarán en África. A empregada adquire así unha dimensión case mítica dentro do relato, en contraste coa súa aparencia máis ben gris e a súa rutina inflexíbel. Unha caracterización que non debe ser pasada por alto, pois está tamén cargada de significado.

Esas dúas mulleres que comparten un cuarto e fan punto febrilmente supoñen unha transposición do ambiente doméstico no eido laboral. A actitude corporal, a disposición física e a indumentaria da máis vella delas subliña esa conexión, esa prolongación do fogar alén dos seus límites. Calzada con zapatillas de abrigo (funcionais, sen tacón nin ningunha outra concesión á coquetería), sostendo no colo un gato, toucada cunha especie de cofia: o seu podería ser o retrato dunha criada ou dunha ama de casa. Dado que a presenza da muller no espazo público non está consolidada, non sorprende descubrir que nel segue a reproducir as maneiras do privado.

Un espazo, o do fogar, que acolle tamén o derradeiro encontro de Marlow e a súa valedora antes de partir para África. Ela recíbeo á hora do té e desprega diante del unha posta en escena idílica, digna pouco menos que do tópico renacentista do locus amoenus. Todo iso "[...] nun cuarto que exercía un profundo efecto sosegante ao mostrarse tal cal se esperaría do salonciño dunha dama", onde tiveron "una unha conversa longa e tranquila ao pé do lume" (Conrad, 2013, p. 22); moi en consonancia coa función de bálsamo para as inquedanzas dos homes que a sociedade vitoriana lles atribuía ás mulleres.

Pero se hai algo característico da conduta da tía é a súa condición de espello da figura do sobriño. Sobre ela, el proxecta a súa imaxe, que ela lle devolve nunha versión idealizada, agrandada, deformada por exceso. As proezas que el imaxina, ela dáas por xa realizadas. A grandeza á que el aspira, para ela é un mérito incuestionábel. Por iso, bule escribirlle á muller dun alto cargo e a outras moitas persoas coa boa nova de que Marlow, “[...] criatura excepcional e rebordante de talento, un bendición para a compañía, un home que non se atopa todos os días" (Conrad, 2013, p. 22) anda á procura dun destino á súa altura. Tal é o empeño que pon en dita tarefa que, á súa chegada a África, Marlow se verá sorprendido pola fama inmerecida que o precede. O seu nome é xa coñecido, está en boca dos membros destacados da compañía. Mesmo Kurtz, illado na selva profunda, dá mostras de recoñecelo cando se atopan. Velaquí un proceso de mitificación. O sobriño adquire así a condi- 
ción de heroe nacional sen tela gañado, mais, a súa sorpresa inicial axiña se transforma en compracencia. O seu triunfo non é senón un espellismo creado pola tía no seu papel de facilitadora.

Convertida nunha superficie reflectinte, esta non posúe máis capacidade que a de absorber e espallar representacións de identidades alleas. E por identidades alleas debe entenderse masculinas. Un rol que entronca coa reflexión que Woolf (1935, pp. 53-54) facía arredor do empequenecemento consciente das mulleres como mecanismo de reforzo do poder dos homes:

Women have served all these centuries as looking-glasses possessing the magic and delicious power of reflecting the figure of man at twice its natural size. Without that power probably the earth would still be swamp and jungle. The glories of all our wars would be unknown. We should still be scratching the outlines of de on the remains of mutton bones and bartering flints for sheep skins or whatever simple ornament took our unsophisticated taste. Supermen and Fingers of Destiny would never have existed. The Czar and the Kaiser would never have worn crowns or lost them. Whatever may be their use in civilised societies, mirrors are essential to all violent and heroic action.

Para que unha posición de privilexio exista e sexa operativa, debe forzarse unha situación de desigualdade, un desequilibrio entre distintas entidades, e proporcionar un discurso que os lexitime. Ou, no seu defecto, dispoñer de instrumentos que sosteñan e mesmo contribúan a aumentar as diferenzas. Tal sería a función da ollada feminina, adestrada para multiplicar a talla masculina, vítima e verdugo da moral patriarcal imperante no contexto que nos ocupa (segundo Simone de Beauvoir, o opresor non sería tan forte se non contase coa complicidade dos propios oprimidos.). "That is why Napoleon and Mussolini both insist so emphatically upon the inferiority of women, for if they were not inferior, they would cease to enlarge" (Woolf, 1935, p. 54).

E nesa función de reforzo da identidade do home conviven en harmonía unha especie de esforzo centrífugo (cooperar co seu éxito social) e outro de signo centrípeto (garantir o seu benestar doméstico). A muller expándese e reprégase en función da axenda masculina. Así, a escena da despedida entre Marlow e a súa tía ten como clímax unha concatenación de xestos típicos desa "ética do coidado" feminina: "despois recibín un abrazo, instrucións de levar roupa de flanela e escribir con frecuencia, etcétera, e partín”. (Conrad, 2013, p. 23) 
Coa partida rumbo ao descoñecido, penetramos nun universo enteiramente masculino: o da aventura. As relacións que se dan nas estacións polas que pasa Marlow son entre homes de distinta procedencia, rango e ambición. Ao contrario que en Pasaxe á India, por exemplo, a relación que se establece aquí entre os territorios colonizados e a metrópole é estritamente comercial, polo que non existe unha estrutura social arredor dos núcleos de explotación. Os asentamentos son instrumentais, orientados ao desempeño de intercambios mercantís. Comunidades de homes que botan man de nativos e de nativas para satisfacer as súas necesidades.

Faise mención, por exemplo, ao xefe de contabilidade da compañía, do que Marlow destaca o seu aspecto pulcro e coidado nun contexto onde o clima e as precarias condicións de vida dificultan até a hixiene máis básica. Curioso, admite:

[...] algún tempo despois non me resistín a preguntarlle como se arranxaba para ir sempre tan impecable. Pasoulle pola cara un levísimo rubor e dixo con modestia:- Estiven a adestrar unha das nativas que andan polo posto. Foi difícil. Non lle prestaba o traballo. (Conrad, 2013, p. 32)

A pequena escala, reprodúcese o patrón de conduta da sociedade de orixe, sometendo á aborixe a unha norma, a da metrópole, que é allea á súa idiosincrasia.

Disolvéndose na masa informe que constitúe a comunidade indíxena aos ollos de Marlow, é esa a única nota de individualidade que se lle concede á muller. É tan insignificante e está tan pouco definida como os homes do seu redor. Cada un ao seu xeito, padecen os efectos prácticos da dominación branca. Até que unha nota discordante vén axitar a calma tensa da selva, xusto no instante en que a aventura acada o seu clímax e Marlow se dispón a repatriar a un Kurtz ás portas da morte.

Quen irrompe é unha salvaxe, "[...] soberbia, de ollos indómitos e maxestosos; o seu avance parsimonioso proxectaba unha sensación de maxestuosidade aciaga" (Conrad, 2013, p. 112). Unha muller caracterizada como un animal, un fera encerrada nun corpo feminino. Unha criatura, en calquera caso, idealizada e fascinante que causa unha fonda impresión en Marlow. A falla de información sobre a súa orixe, identidade ou papel naquel contexto, na súa mente grávase un retrato que, a pesar do paso do tempo, é quen de evocar en forma de detallada prosopografía para os seus interlocutores: 
Camiñaba con pasos mesurados, envolveita en teas de listas rematadas con flocos, e pisaba a terra con orgullo, cun lixeiro tintinar e relampar de alfaias bárbaras.Andaba coa cabeza moi alta, o cabelo estaba peiteado en forma de caso, levaba polainas de bronce até os xeonllos, luvas de fío de bronce até os cóbados, tiña un círculo escarlata na meixela tostada, innumerables colares de doas de vidro ao pescozo, adornos estrafalarios, amuletos, galanos de feiticeiros pendurados por todo o corpo, a escintilar e a tremer con cada paso. (Conrad, 2013, p. 112)

Unha descrición que induce a pensar que se trata dunha figura preeminente dentro da comunidade, tan rica é a súa vestimenta e solemne a súa maneira de conducirse. A súa actitude feroz, desafiante, agresiva podería inducirnos a pensar que está despregando xa sexa un ritual defensivo ou de dó pola marcha de Kurtz. É acaso a súa escrava? A suntuosidade da súa roupa desmínteo. A súa amante africana? A dúbida queda suspendida no aire mentres a comitiva europea se afasta río abaixo. Na beira, a muller aglutina a multitude arredor dela, sinal do seu poder.

De súpeto abriu os brazos nus e botounos ao aire, ríxidos, por riba da cabeza, coma movida por un desexo incontrolable de tocar o ceo, e ao mesmo tempo as sombras céleres correron pola terra, rodopiaron no río, apertando o vapor nun abrazo avesío. (Conrad, 2013, p. 113)

O seu é o poder que xurde da terra, das tebras, da vida fecunda, misteriosa e apaixonada que se cerne sobre os estranxeiros para aprisionalos nas súas fauces; unha visión non exenta de exotismo. Nela conflúen a escuridade -a da súa pel, a da selva, a das terras aínda descoñecidas- e a luz -que ela irradia e que provén dos abelorios, mais tamén da súa actitude non submisa-, as dúas forzas en combate entre as liñas da novela. Velaquí unha criatura que reloce entre o negror, un punto de inflexión, unha nova ponte simbólica entre dous mundos.

Como un cometa, a súa fulgurante aparición esvaécese na trama para precipitarnos cara ao desenlace da expedición de Marlow. Atrás quedou África e os seus contrastes, atrás, os derradeiros días de Kurtz; os acontecementos devólvennos ao continente europeo, a esa casa reconfortante na que semella pecharse o círculo da aventura. Alí, o heroe que non foi tal entrégase ás atencións da tía, afanada agora en axudarlle a recuperar a saúde. E de novo sae a relucir a súa faceta de coidadora, repregada no asistencial, no puramente doméstico. 
Un entorno case simétrico ao que enmarca o encontro entre Marlow e a derradeira figura feminina que intervén na historia: a prometida de Kurtz, unha denominación baleira de contido, pois, morto este, a promesa de matrimonio é unha posibilidade que se esfarelou no aire. Porén, o narrador segue a definila en relación ao defunto, xa non como "futura muller de", senón como viúva a ollos da sociedade (posto que a Igrexa non a recoñece). Unha imaxe que ela cultiva e na que persevera: "Estaba de loito. Había máis dun ano que el morrera, máis dun ano dende que chegara a nova; parecía disposta a recordar e gardar loito para sempre" (Conrad, 2013, p. 136).

Ao contrario que no caso das empregadas da compañía colonial ou da propia tía, a prometida é descrita como un ser inerte. Non executa acción ningunha. Semella que o seu único cometido sexa lembrar a Kurtz, converterse na memoria viva do seu paso pola Terra ("eu había gardar coma un tesouro até o último suspiro, até a última palabra, até o último sinal, até a última mirada" [Conrad, 2013, p. 149]). Unha muller ao servizo da gloria masculina, outra variante do espello que agranda o ego do home. Este adquire nas súas palabras unha dimensión extraordinaria, rozando o hiperbólico: "Que gran perda sufro. Sufrimos -corrixiuse con fermosa xenerosidade. Logo engadiu, nun murmurio-: O mundo enteiro" (Conrad, 2013, p. 139). Mais o dramatismo do seu pesar non é incompatíbel cunha inesperada reivindicación da posición que ocupaba como compañeira del. Ela dise coñecedora dos seus plans, o que significa que el a fixera partícipe dos mesmos. Tal afirmación é rebaixada, disimulada por unha sutil fórmula de captatio benevolentiae: "tamén eu os coñecía, e quizais non era capaz de entendelos, pero outros sabían deles" (Conrad, 2013, p. 139). Poida que dende un punto de vista retórico estea a rebaixarse intelectualmente, asumindo a inferioridade intelectual que a sociedade da época lle presupón, pero o simple feito de estar ao tanto parece demostrar o contrario. Kurtz tíñaa en consideración, e ela sublíñao con orgullo.

Porén, esa pequena fenda na súa imaxe de muller que sofre, ese minúsculo destello de amor propio, esmorece a medida que avanza a súa conversa con Marlow. Precisa con urxencia que este lle confirme que Kurtz morreu pensando nela. Non polo sentido romántico de dito xesto: pola necesidade de reafirmar unha identidade construída en relación á del. Ante a presión, Marlow opta por mentir. Si, o heroe pronunciou o seu nome antes de expirar. De que serviría atormentar a esa muller, a ese anxo de cabelos louros, rostro pá- 
lido, fronte pura e ollos escuros, cos berros horrorizados do seu prometido? "Non, ela non podía ter nada que ver. Tiñan vostedes que oír como o corpo resucitado do señor Kurtz dicía 'a miña futura'. Daquela habían percibir de inmediato até que punto era ela allea a todo aquilo" (Conrad, 2013, p. 126).

E pecha así o relato, recuperando o discurso en defensa do feliz illamento das mulleres fronte aos aspectos menos felices da existencia, fronte á escuridade desta. Nin África nin a boa sociedade europea eran lugar para elas.

\section{Bibliografía}

Bourdieu, P. (1998). La domination masculine. Seuil.

Brooks, P. (1984). Reading for the plot. Design and Intention in Narrative. Clarendon Press.

Conrad, J. (2009). O corazón do negror. Faktoría K de Libros.

Eagleton, T. (2005). The English Novel: An Introduction. Blackwell Pub.

Hawthorn, J. J. (1990). Foseph Conrad. Narrative Technique and Ideological Commitment. Edward Arnold.

Hough, G. (1960). Image and Experience: Studies in a Literary Revolution. Duckworth.

Jones, S. (1999). Conrad and Women. Oxford University Press.

Najder, Z. (2007). Foseph Conrad: A Life. Camden House.

Said, E. W. (1996). Cultura e imperialismo. Anagrama.

Showalter, E. (1985). The Female Malady. Women, Madness and English Culture, 18301980. Virago Press.

Smith, J. M. (1989). "Too Beautiful Altogether": Patriarchal Ideology in HD. En R. C. Murfin (Ed.), Joseph Conrad. Heart of Darkness. A Case Study in Contemporary Criticism (179-195). St. Martin's Press.

Watt, I. (1980). Conrad in the Nineteenth Century. Chatto \& Windus.

Woolf, V. (1935). A Room of One's Own. The Hogarth Press.

Woolf, V. (1984). A Haunted House and Other Short Stories. The Hogarth Press. 